\title{
Artur Czapiga
}

Uniwersytet Reszowski (Polska)

\section{APROBATA ZAPOWIEDZIANA W CZECŚCI NARRACYJNEJ (NA MATERIALE JĘZYKA POLSKIEGO, ROSYJSKIEGO I ANGIELSKIEGO)}

Celem niniejszego opracowania jest ustalenie zbioru jednostek leksykalnych predestynowanych do pełnienia pragmatycznej funkcji aprobaty, a następnie ich analiza w świetle teorii aktów mowy.

Postrzeganie mówienia jako działania zostało rozpropagowane przez Johna Austina w połowie ubiegłego wieku (1962). Pomimo tak krótkiej historii teoria aktów mowy doczekała się jednak całkiem pokaźnej bibliografii przedmiotu, a mnogość podejść poszczególnych badaczy zaowocowała sporym zamieszaniem w samej choćby terminologii (Lipczuk 2000). Jednym z podstawowych wyzwań podczas analizy pragmalingwistycznej jest próba podziału naturalnie ciągłej wypowiedzi na wyraźnie oddzielone segmenty, a następnie jednoznaczne przyporządkowanie ich konkretnym klasom. Taki proces opiera się w znacznym stopniu na subiektywnej ocenie badacza, a u jego podstaw leży zwykle tylko jedno kryterium (Czamara 1977: 170), np. semantyka czasowników performatywnych (Austin 1962: 67-73), kryterium prawdziwości (Wunderlich 1978: 77), miejsce danego aktu mowy w strukturze dialogu (Weigand 1989: 83) itd.

Teoretyczną podstawę niniejszych rozważań stanowi teoria aktów mowy zaproponowana przez Johna Searle'a, według której punktem wyjścia do studium tego zjawiska jest illokucyjny cel wypowiedzi (1969: 54-56). Za wiodący aspekt $\mathrm{w}$ badaniu illokucyjnej siły wypowiedzi uznajemy analizę funkcji pragmatycznych - w postaci postulowanej przez Aleksa Awdiejewa (1983: 53-88; 2007).

Opisywane zjawisko aprobaty rozumiane jest jako 'uznanie czegoś za dobre, słuszne, godne poparcia i zgoda na to' (Szymczak 1987); aprobata 'czyichś działań, planów lub czyjegoś stanowiska w jakiejś sprawie, to ich pochwała i przychylna zgoda na nie' (Bańko 2000). Słowniki języka rosyjskiego podają następujące definicje: Одобрение to 'признание хорошим, правильным; положительный отзыв, похвала' (Кузнецов 2009); 'отзыв, выражающий похвалу, признание успеха’ (Шведова 1998), a także ‘похвала, одобрительный отзыв’ (Ожегов, 
Шведова 1998). Anglojęzyczny materiał leksykograficzny prezentuje bardzo podobną interpretację tego leksemu: approval - 'the belief that something or someone is good or acceptable, a good opinion of someone or something, permission to do something, acceptance of an idea, action, plan, etc. often may suggest considerable esteem or admiration' (Gove 2011).

Ciekawą interpretację znaczenia opisywanego aktu mowy proponuje A. Wierzbicka. W jej taksonomii aprobata należy do obszerniejszej grupy zezwoleń (permit group: Wierzbicka 1987: 120-122), a jej analiza idzie w dwóch kierunkach - po pierwsze jako aktu wyrażanego przez przełożonego, po drugie jako aktu mentalnego, wyrażającego prymarnie moralną ocenę sytuacji. Dla obydwu punktów widzenia przewidziana jest oddzielna peryfraza. Por.:

\section{Aprobata 1}

Wiem, że X chce doprowadzić do tego, żeby zdarzyło się $\mathrm{Y}$,

zakładam, że X rozumie, że on nie jest w stanie tego zrobić, jeśli ja mu nie powiem, że ja uważam, że dobrze, żeby to się zdarzyło,

zakładam, że ja jestem tym, który powinien powiedzieć, czy uważam, że to dobrze, żeby to się zdarzyło,

wypowiadam: uważam, że to dobrze,

wypowiadam to, ponieważ chcę doprowadzić do tego, żeby $\mathrm{X}$ był w stanie zdziałać $Y$,

zakładam, że z tego powodu X to zdziała (Wierzbicka 1987: 120, thum. A. Cz.).

Warto zaznaczyć, że w tej interpretacji aktu aprobaty wygłaszająca go osoba pełni w danej sytuacji dialogowej pozycję wyższą niż słuchacz. Nie chodzi tu tylko o przełożonego $\mathrm{w}$ wąskim znaczeniu osoby zajmującej wyższe stanowisko w hierarchii danej organizacji, lecz także, czy może raczej - przede wszystkim - o osobę mającą $\mathrm{w}$ momencie mówienia przewagę nad rozmówcą co do kompetencji, wiedzy, doświadczenia, władzy itd., w wyniku czego to właśnie w gestii nadawcy leży zezwolenie na wykonanie czynności znajdującej się w propozycji aktu aprobaty.

Aprobata 2

Myślę o kimś, robiącym Y, uważam, że dobrze jest tak robić,

wyobrażając sobie, że X mówi do mnie: nie mogę zrobić tego, co chcę zrobić, jeśli ty nie powiesz, że ty uważasz, że to dobrze, żeby tak zrobić,

wypowiadam: myślę, że to dobrze, żeby tak zrobić,

wypowiadam to, ponieważ chcę powiedzieć, co ja o tym myślę (Wierzbicka 1987: 121, tłum. A. Cz.). 
Także i w tym typie opisywanego aktu mowy bardzo ważne są role społeczne adresata ${ }^{1}$, jednak za podstawę tego typu aprobaty przyjmuje się pozytywną ocenę czyichś poczynań, przeprowadzoną na poziomie mentalnym (Wierzbicka 1987: 121). Zgadza się to w pełni z podejściem Waldemara Grzybowskiego, który zauważa, iż z punktu widzenia etyki aprobata jest wynikiem sądów moralnych (Grzybowski 1985: 169).

W niniejszych rozważaniach przyjmujemy, że akt mowy aprobaty łączy w sobie obydwa aspekty wyróżnione przez A. Wierzbicką, a dotychczasowe badania (Czapiga 2009: 42-46; 2012: 20-27) pozwalają traktować akt mowy aprobaty, речевой акт одобрения oraz speech act of approval jako ekwiwalenty, realizujące te same funkcje pragmatyczne.

Materiał faktograficzny zebrany na potrzeby niniejszego szkicu pochodzi z internetowych korpusów języka polskiego ${ }^{2}$, rosyjskiego ${ }^{3}$ i angielskiego ${ }^{4}$. Podstawowym kryterium wyboru było pochodzenie przykładów z dialogu, gdy dana wypowiedź została zapowiedziana w części narracyjnej jako aprobata ${ }^{5}$. Taki właśnie dobór materiału pozwala ominąć etap analizy znaczenia i ukrytych sensów danej repliki, gdyż, z założenia, akt aprobaty jest obecny w każdym z zebranych wypowiedzeń.

Pod względem ilości znalezionych przykładów zdecydowanie najskromniej wypadł materiał polskojęzyczny. W próbce około 240000000 słów tylko 6 wypowiedzi spełniło wszystkie kryteria wyszukiwania. Materiał rosyjskojęzyczny okazał się najbogatszy - z próbki około 230000000 słów zostało wyekscerpowanych 158 wypowiedzi, natomiast w materiale anglojęzycznym - 49 przykładów przypadło na próbkę około 100000000 słów.

Zdecydowanie najczęściej występują wypowiedzi proste, składające się z jednego, dwóch lub trzech słów (1a, 1b, 1c). Przeważają akty mowy o prostej strukturze (Czapiga 2013: 21-29), zawierające tylko część wyrażającą opisywany akt mowy, bez zwrotu adresatywnego czy wyjaśnienia motywacji udzielenia aprobaty (1a, 1b, 1c). Bardzo rzadko występują akty zawierające tylko wytłumaczenie motywacji wystawienia pozytywnej oceny propozycji, bez pozostałych elementów (1g). Spośród aktów o rozwiniętej strukturze elementem dodanym jest najczęściej zwrot adresatywny (1d, 1e, 1f). Tylko sporadycznie spotykamy repliki obejmujące dłuższe urywki tekstu, w całości pełniące funkcję aprobaty

1 Rodzice mogą zaaprobować decyzję syna, jednak syn nie może (w standardowej sytuacji komunikacyjnej w opisywanych kulturach) zaaprobować decyzji swoich rodziców. Podobnie w przypadku par nauczyciel - uczeń, dyrektor - pracownik, oficer - szeregowiec itd.

2 http://www.nkjp.uni.lodz.pl/ (29.01.2015).

$3 \mathrm{http}: / /$ www.ruscorpora.ru/search-main.html (28.01.2015).

4 http://www.natcorp.ox.ac.uk/ (27.01.2015).

5 Przy czym zapowiedź musi zawierać czasownik aprobować, одобрять, approve w dowolnej formie lub inne zwroty z wyrazami pokrewnymi i znaczeniem wprowadzanym ww. czasownikami, np. wyrazil aprobate, высказал свое одобрение, expressed approval. 
(1h - w tym przypadku replika zawiera zarówno część wyrażającą aprobatę, zwrot adresatywny, jak i rozbudowane wyjaśnienie). Zob.:

1a

-A-zaaprobowat Edzio.

$1 \mathrm{~b}$

- Вот именно! - одобрил его молчание Максим.

$1 \mathrm{c}$

Ross turned his dark head to give her a broad smile of approval. 'Clever girl!'

$1 \mathrm{~d}$

- Stuszne, stuszne racje, dobrodzieju! - ozwat się aprobująco.

$1 \mathrm{e}$

- Хорошо поешь, сынок, - одобрил Яков.

1f

'Fine plan you have there, Pat, 'said the President approvingly. 'I like it.'

$1 \mathrm{~g}$

-W ten sposób będzie wilk syty i owca cała... - zaaprobowat decyzję Wilmowski.

$1 \mathrm{~h}$

Отеи тоже удивился, но одобрил: - Правильно, сынок! Мьл в пригороде родились и померли б там, если б завод квартиру не дал, а ты выбивайся в люди! Дипломатом станешь.

Najczęstszymi sposobami wyrażenia aprobaty w materiale rosyjskojęzycznym są leksemу правильно (2a), молодеи (2b), хорошо (2c) oraz połączenie это + przysłówek (2d). Dla języka angielskiego jest to przymiotnik good (2e) oraz konstrukcja that is + przymiotnik (2f) lub rzeczownik (2g):

$2 \mathrm{a}$

- И правильно, - одобрил Фёдор.

$2 \mathrm{~b}$

- Молодец! - одобрил он. - Так и надо рассуждать!

$2 \mathrm{c}$

- Хоромо, - одобрил генерал.

$2 \mathrm{~d}$

- Это отлично, - одобрил Димка.

$2 \mathrm{e}$

'Good.' Eve approved of that. 
$2 \mathrm{f}$

'That is proper, 'she said approvingly.

$2 \mathrm{~g}$

'That's the way,' Rodney approved.

Z powodu małej liczby przykładów w języku polskim nie ma możliwości ustalenia najpopularniejszych zwrotów dla tego materiału.

Stylistyczny charakter opisywanych wypowiedzeń jest mało różnorodny. Przeważają formy neutralne $(2 \mathrm{a}-2 \mathrm{~g})$, rzadko pojawiają się stylizacje na język młodzieżowy (3a, 3b, 3c):

$3 \mathrm{a}$

- Шик, - одобрил Криворотов новый Аринин наряд.

$3 \mathrm{~b}$

- Класс! - одобрила Люлька.

$3 \mathrm{c}$

'There, 'she said approvingly, 'You look smashing.'

Wzmocnienie przekazu danego aktu mowy za pomocą powtórzenia (4a, 4b, 4c), intonacji (4c, 4d, 4e) czy doboru odpowiedniego słownictwa (4f, 4g) występuje rzadko. Możliwe jest także uzyskanie tego efektu przez użycie określenia odnoszącego się do czasownika zapowiadającego aprobatę w części narracyjnej (4h, 4i), jednak opisywany akt mowy, jeśli jest wprowadzony przez narratora, to przyjmuje najczęściej formę stonowaną (4j, 4k, 4l). Z kolei zmniejszenie mocy aprobaty osiągane bywa przez użycie leksemów osłabiających pozytywną ocenę (4m) lub przez wprowadzenie w części narracyjnej adekwatnej informacji (4n). Zob.:

$4 \mathrm{a}$

'Very, very pretty, 'she approved, aloud.

$4 \mathrm{~b}$

- Ничего, ничего, правильно, - одобрил Левочка. - Так ему и надо!

$4 \mathrm{c}$

- Stuszne, stuszne racje, dobrodzieju! - ozwat się aprobująco.

$4 \mathrm{~d}$

- И то верно! - одобрил Вадим. - Молодеи, соображаешь!

$4 \mathrm{e}$

Ross turned his dark head to give her a broad smile of approval. 'Clever girl!' 
$4 \mathrm{f}$

'There, 'she said approvingly, 'You look smashing.'

$4 \mathrm{~g}$

- Класс! - одобрила Люлька.

$4 \mathrm{~h}$

Lachlan eagerly approved. 'Dhia! Why did I not think of that, then?'

$4 \mathrm{i}$

- Вот это ты молодец! Это - по-нашенски! Так их! - восторженно одобрил его тот.

$4 \mathrm{j}$

- Dobrze zadziałat-zaaprobowat chłopak nieuważnie.

$4 \mathrm{k}$

- Пусть. - одобрил Иван Дмитриевич.

41

'That's better,' he murmured approvingly.

$4 \mathrm{~m}$

Одобрил: - Неплохая квартира.

$4 \mathrm{n}$

- Молодияы. Быстро схватываете, - сквозь зубы одобрил Забелин.

W niniejszym opracowaniu w centrum zainteresowania znajdują się tylko werbalne sposoby wyrażenia aktu mowy aprobaty. Należy jednak zaznaczyć, że w przeanalizowanym materiale znajdującej się w części narracyjnej zapowiedzi aprobaty często towarzyszą pozawerbalne środki ekspresji, takie jak kiwnięcie głową, nieartykułowany okrzyk czy aprobujące spojrzenie (5a, 5b, 5c):

$5 \mathrm{a}$

Julia kiwała aprobująco glowa. Ale ustyszawszy cenę, z żalem odkładała bucik; nie chciała przyjąc od Julii pożyczki.

$5 \mathrm{~b}$

На банкете после спектакля взволнованный величием происшедшего директор, провозгласив тост за здоровье живого классика, выдвинул предложение назвать театр его именем. Это было одобрено единогласным ревом пьяных и счастливых голосов.

$5 \mathrm{c}$

Which somewhat spoiled the metre, but there you go. Laura looked approvingly upon all the little 'sold'stickers dotting the finest furniture of the room. 
W materiale polskojęzycznym i anglojęzycznym przykłady tego typu są wielokrotnie liczniejsze od werbalnych. W materiale pochodzącym z języka rosyjskiego są one mniej liczne, za to zwraca uwagę fakt, że bardzo często czasownik одобрить oznacza nie zapowiedź aktu mowy aprobaty w dialogu, lecz akt o charakterze prawnym - pozytywną ocenę czynności i zgodę na nią, wydaną przez uprawnioną do tego osobę lub instytucję.

Część wyekscerpowanych wypowiedzi zawiera jednostki leksykalne, mogące oprócz zapowiedzianej aprobaty pełnić dodatkowe funkcje pragmatyczne. Najczęściej spotykanym aktem mowy, towarzyszącym opisywanej aprobacie, jest pochwała $(6 \mathrm{a}, 6 \mathrm{~b}, 6 \mathrm{c})$ :

$6 \mathrm{a}$

Ciotka aprobująco kiwnęła głowa. - Eadnie to powiedziałeś.

$6 \mathrm{~b}$

- Молодеи! Смышленый мальчик, - облегченно одобрил Ознобихин.

$6 \mathrm{c}$

'Well done, Tory, that's my girl, 'her father approved at once.

Formułując wnioski wynikające z przeprowadzonego badania należy pamiętać o specyfice materiału empirycznego - kryterium doboru mocno ograniczyło ilość zebranych przykładów i zawęziło zakres badanego materiału do utworów narracyjnych z częściami dialogowymi. $Z$ drugiej jednak strony, powyższe ograniczenia pozwoliły wyłonić grupę przykładów o wysokiej jednoznaczności intencji Nadawcy.

W polskojęzycznym materiale zdecydowanie dominują niewerbalne sposoby wyrażania aprobaty (kiwnięcie głową, ruch ręką, spojrzenie itp.), natomiast opisywane w niniejszym szkicu werbalne wykładniki aprobaty zapowiedzianej w części narracyjnej stanowią zaledwie ułamek wyekscerpowanych przykładów. Niewielka ich ilość (zaledwie 6) nie pozwala wyciągnąć ogólnych wniosków dotyczących tendencji dla danego języka.

W materiale rosyjskojęzycznym po zapowiedzi aprobaty najczęściej występuje replika dialogowa zawierająca prostą ocenę propozycji rozmówcy (bezpośrednio - samej propozycji, lub pośrednio - przez pozytywną ocenę samego pomysłodawcy). Charakter stylistyczny replik w większości przypadków jest pozbawiony nacechowania emocjonalnego.

$\mathrm{W}$ materiale anglojęzycznym przeważają niewerbalne sposoby przekazania aprobaty, natomiast wśród analizowanych w niniejszym szkicu językowych wykładników tego aktu mowy najwięcej jest wypowiedzi prostych, które - podobnie jak w przypadku materiału rosyjskojęzycznego - nie są nacechowane stylistycznie i nie odzwierciedlają silnych emocji. 
Przeprowadzona analiza wpisuje się w znacznie szerszy plan badań nad charakterem aktu mowy aprobaty. Poczynione obserwacje mogą stanowić podstawę do rozwiązywania kolejnych problemów, dotyczących choćby obiektu aprobaty, Nadawcy i Odbiorcy tego aktu mowy czy kontekstu zaistniałej sytuacji komunikacyjnej.

\section{Bibliografia}

Austin J. L. (1962), How to Do Things with Words, Oxford.

Awdiejew A. (1983), Klasyfikacja funkcji pragmatycznych, „Polonica” IX, s. 53-88.

Awdiejew A. (2007), Gramatyka interakcji werbalnej, Kraków.

Czapiga A. (2009), Formalne wyktadniki aprobaty w języku polskim, rosyjskim i angielskim, [w:] Świat Stowian w języku i kulturze X. Językoznawstwo. Semantyka. Pragmatyka. Kognitywizm, red. E. Komorowska, Ż. Kozicka-Borysowska, Szczecin, s. 42-46.

Czapiga A. (2012), Analiza pragmatyczna wypowiedzeń zawierajacych leksemy aprobować, одобрять, to approve, „Zeszyty Naukowe Uniwersytetu Rzeszowskiego. Zeszyt 76. Seria Filologiczna. Glottodydaktyka 4", s. 20-27.

Czapiga A. (2013), Struktura aktu mowy aprobaty (na materiale języka polskiego, rosyjskiego i angielskiego), „Zeszyty Naukowe Uniwersytetu Rzeszowskiego. Zeszyt nr 80. Seria Filologiczna. Glottodydaktyka 5", Rzeszów, s. 21-29.

Czamara A. (1977), Wartościujący akt illokucyjny, „Polonica” XVIII, s. 169-174.

Inny słownik języka polskiego (2000), tom I-II, red. M. Bańko, Warszawa.

Grzybowski W. (1985), O znaczeniach czasowników aprobować i zgadzać się, „Polonica” IX, s. $169-177$.

Lipczuk R. (2000), O wielości i wieloznaczności terminów (na przykładzie klasyfikacji aktów mowy), „Acta ac Communitas”, nr 9, s. 169-176.

Gove P. B., (ed.) (2011), Webster's Third New International Dictionary, www.m-w.com (12.01.2015)

Weigand E. (1989), Sprache als Dialog. Sprachakttaxonomie und kommunikative Grammatik, Tübingen.

Wierzbicka A. (1987), English Speech Act Verbs, Sydney.

Wunderlich D. (1978), Studien zur Sprechakttheorie, Frankfurt/M.

Searle J. R. (1969), Speech Acts: An Essay in the Philosophy of Language, Cambridge.

Stownik języka polskiego (1978), tom I, red. M. Szymczak, Warszawa.

Большой толковый словарь русского языка (2009), ред. С. А. Кузнецов, Санкт-Петербург.

Ожегов С. И., Шведова Н. Ю. (1998), Толковый словарь русского языка, Москва.

Русский семантический словарь (1998), ред. Н. Ю. Шведова, Москва.

\section{Korpusy}

http://www.nkjp.uni.lodz.pl/ (29.01.2015).

http://www.ruscorpora.ru/search-main.html (28.01.2015).

http://www.natcorp.ox.ac.uk/ (27.01.2015). 


\section{Artur Czapiga \\ APPROVAL INTRODUCED IN THE NARRATIVE PART (ON THE EXAMPLE OF POLISH, RUSSIAN AND ENGLISH)}

(Summary)

The article is devoted to the analysis of the ways of expressing the speech act of approval in Polish, Russian and English. The material has been gathered from corpora, and only the examples have been taken into consideration where the phrase uttered by a speaker is introduced in the narration part as approval. This method of collecting material gives the opportunity to avoid misunderstanding in the process of the interpretation of the speaker's intentions.

It occurs that approval introduced in the narrative part of a text is more often nonverbal in Polish and English materials. The lexical markers of the speech act under investigation display a considerable number of similarities between Polish, Russian and English examples. The utterances are usually stylistically neutral and they are generally simple in structure.

Keywords: Speech acts, approval, Polish, Russian, English.

\section{APROBATA ZAPOWIEDZIANA W CZECŚCI NARRACYJNEJ (NA MATERIALE JEZZYKA POLSKIEGO, ROSYJSKIEGO I ANGIELSKIEGO)}

(Streszczenie)

Artykuł poświęcony jest analizie sposobów wyrażenia aktu mowy aprobaty w języku polskim, rosyjskim i angielskim. Materiał pochodzi z korpusów badanych języków, i obejmuje przypadki, gdy wypowiedź nadawcy jest zapowiedziana w części narracyjnej tekstu jako aprobata. Dzięki zastosowaniu tej metody zbierania materiału można uniknąć wątpliwości związanych z procesem interpretacji intencji nadawcy wypowiedzi.

Słowa kluczowe: akty mowy, aprobata, język polski, język rosyjski, język angielski. 